\title{
Small Bowel Perforation as a Consequence of Strangulated Direct Inguinal Hernia
}

\author{
Sherif Monib ${ }^{1}$, Ahmed Hamad ${ }^{2}$, Hany F. Habashy ${ }^{3}$ \\ 1. Breast Surgery, West Hertfordshire Hospitals NHS Trust, St. Albans and Watford General Hospitals, London, GBR 2. \\ Breast Surgery, University Hospitals of Derby \& Burton, Derby, GBR 3. Surgical Oncology, Faculty of Medicine Fayoum \\ University, Faiyum, EGY
}

Corresponding author: Sherif Monib, sherif.monib@nhs.net

\begin{abstract}
Inguinal hernia is probably one of the most common surgical conditions, with strangulation accounting for a good number of acute surgical admissions. It has always been known that direct hernias are less likely to strangulate due to wide hernial defects in comparison to indirect hernia. For that reason, some surgeons do not attempt repair of direct hernias in elderly patients. We present a relatively uncommon case of a 58-yearold gentleman who presented with clinical signs of an incarcerated inguinal hernia; which was found at exploration to be a strangulated direct hernia with small bowel perforation. We believe that direct inguinal hernia should always be included in the differential diagnosis of incarcerated or strangulated groin hernia.

Categories: General Surgery

Keywords: groin, hernia, strangulated, bowel perforation, inguinal hernia

\section{Introduction}

Inguinal hernia repair is probably one of the most common procedures in general surgery. Yet, sometimes it can be a diagnostic challenge a fact that can be attributed to the complex anatomy of the groin. It has always been believed that direct hernias are less likely to present with strangulation due to the relatively wide neck in comparison to indirect inguinal hernia. Based on that, some surgeons do not attempt to direct inguinal hernia repair in older patients. However, one study showed that age is the most important prognostic factor for strangulation, with increased incidence in older patients; they also found that the average diameter of the transversalis fascia hernia defect was $23.8 \mathrm{~mm}$. Hence, they concluded that the diameter of the hernial defect is not directly related to the incidence of strangulation [1].
\end{abstract}

Review began 12/10/2020 Review ended 12/14/2020 Published 12/20/2020

(c) Copyright 2020

Monib et al. This is an open access article distributed under the terms of the Creative Commons Attribution License CC-BY 4.0., which permits unrestricted use, distribution, and reproduction in any medium, provided the original author and source are credited.

\section{Case Presentation}

We are presenting a case of a 58-year-old gentleman who presented to the accident and emergency department with a tender right groin swelling of about 36-hour duration, following heavy object lifting, pain was dull aching in character and progressively increasing in intensity. His past medical history included that he was a heavy smoker who smoked about 20 cigarettes per day for about 20 years, and he has been suffering from right groin pain every time he lifted or pushed any heavy object with no other medical conditions of significant importance. General examination was unremarkable; his vital signs were within normal apart from tachycardia of $90 \mathrm{bpm}$. Abdominal examination revealed lax abdomen with no palpable masses or organomegaly, a tender right direct/indirect inguinal hernia, with no impulse on cough, scrotal examination was normal (Figure 1). 


\section{Cureus}

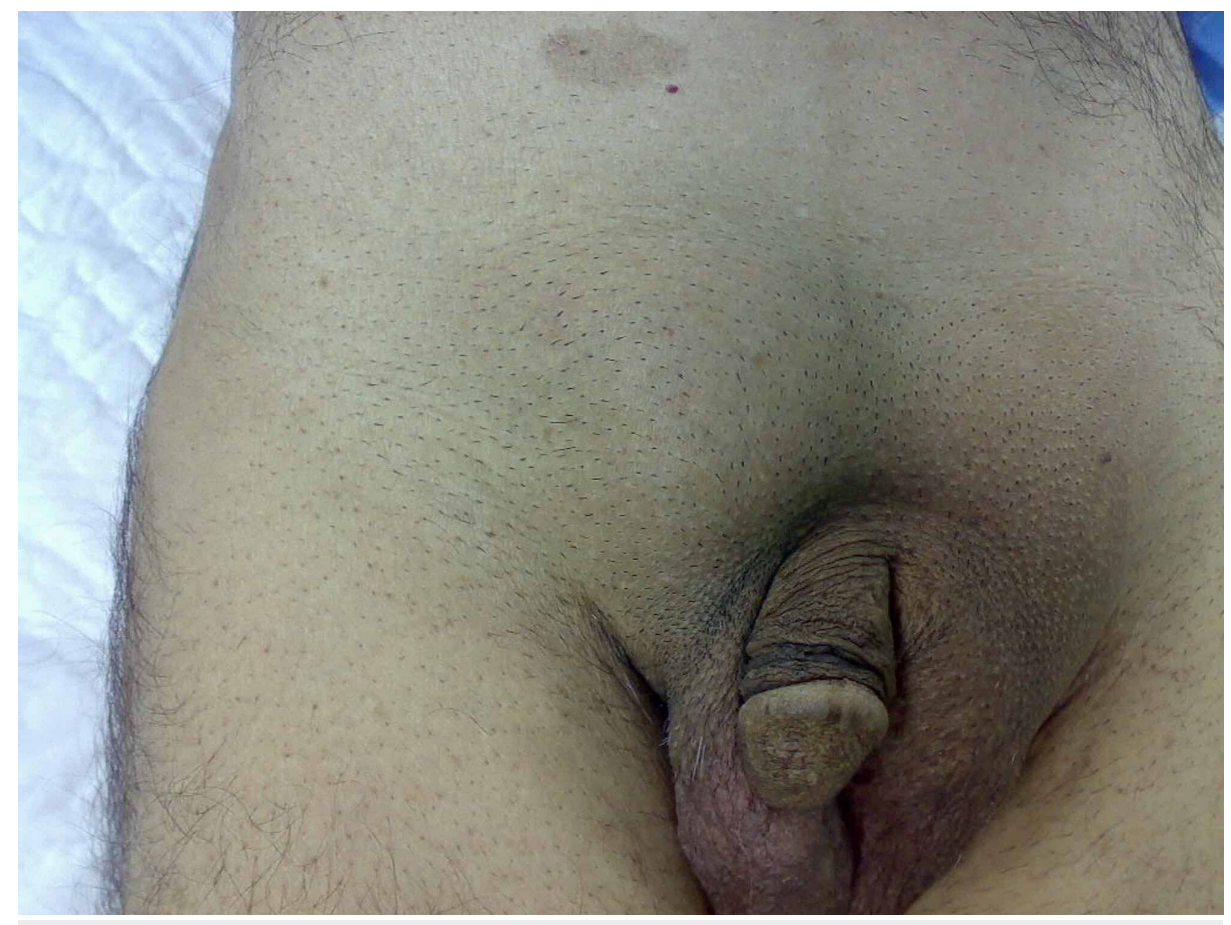

FIGURE 1: Preoperative photo showing the right groin swelling.

All his blood were within normal range; no scans were done at that time. The provisional diagnosis was an incarcerated inguinal hernia, so he was consented and taken to the theatre for repair of the inguinal hernia. At operation, it was found to be a strangulated direct hernia containing a perforated loop of the terminal ileum (Figures 2, 3).

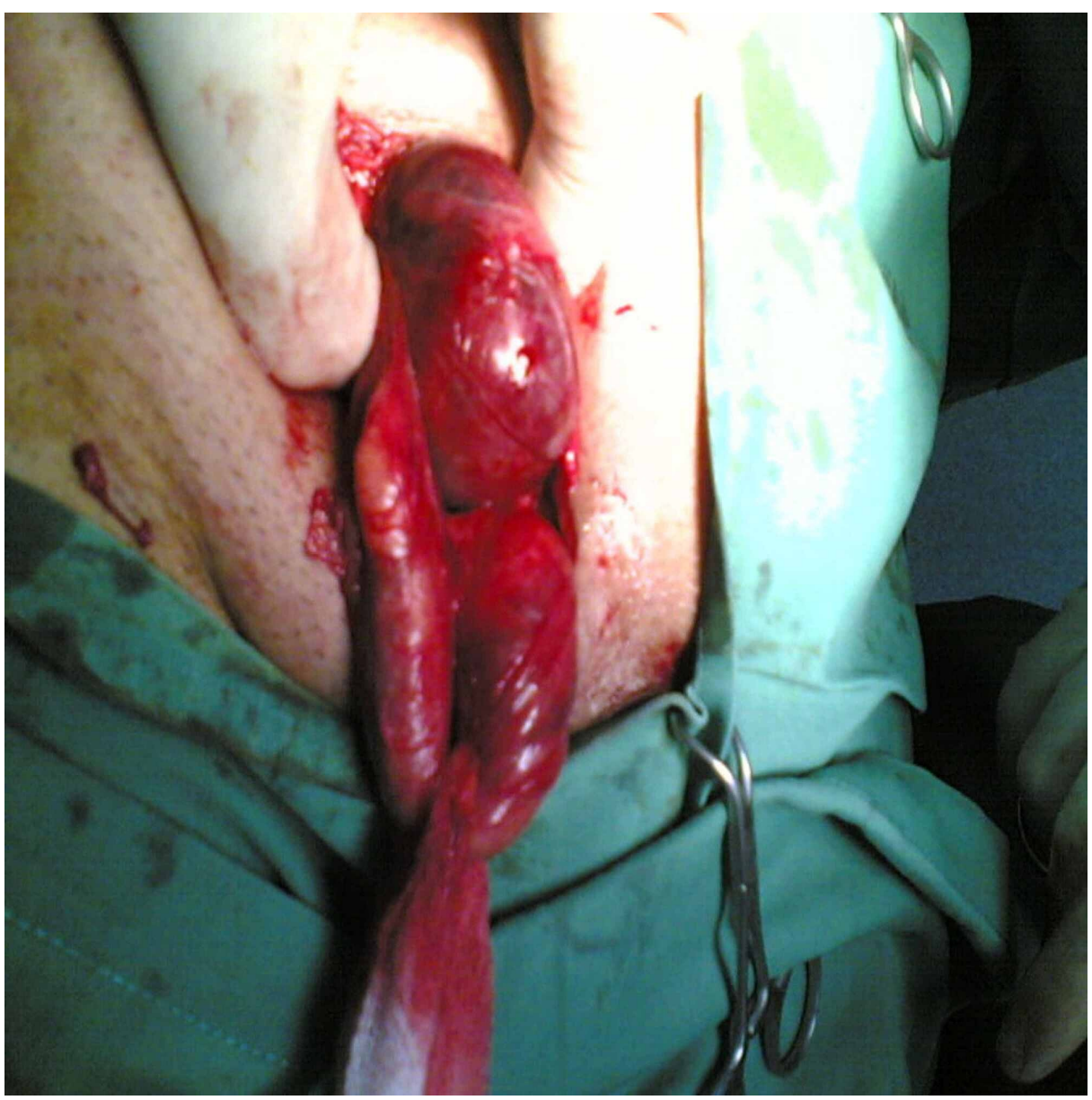




\section{Cureus}

FIGURE 2: Intraoperative photo showing the direct hernia.

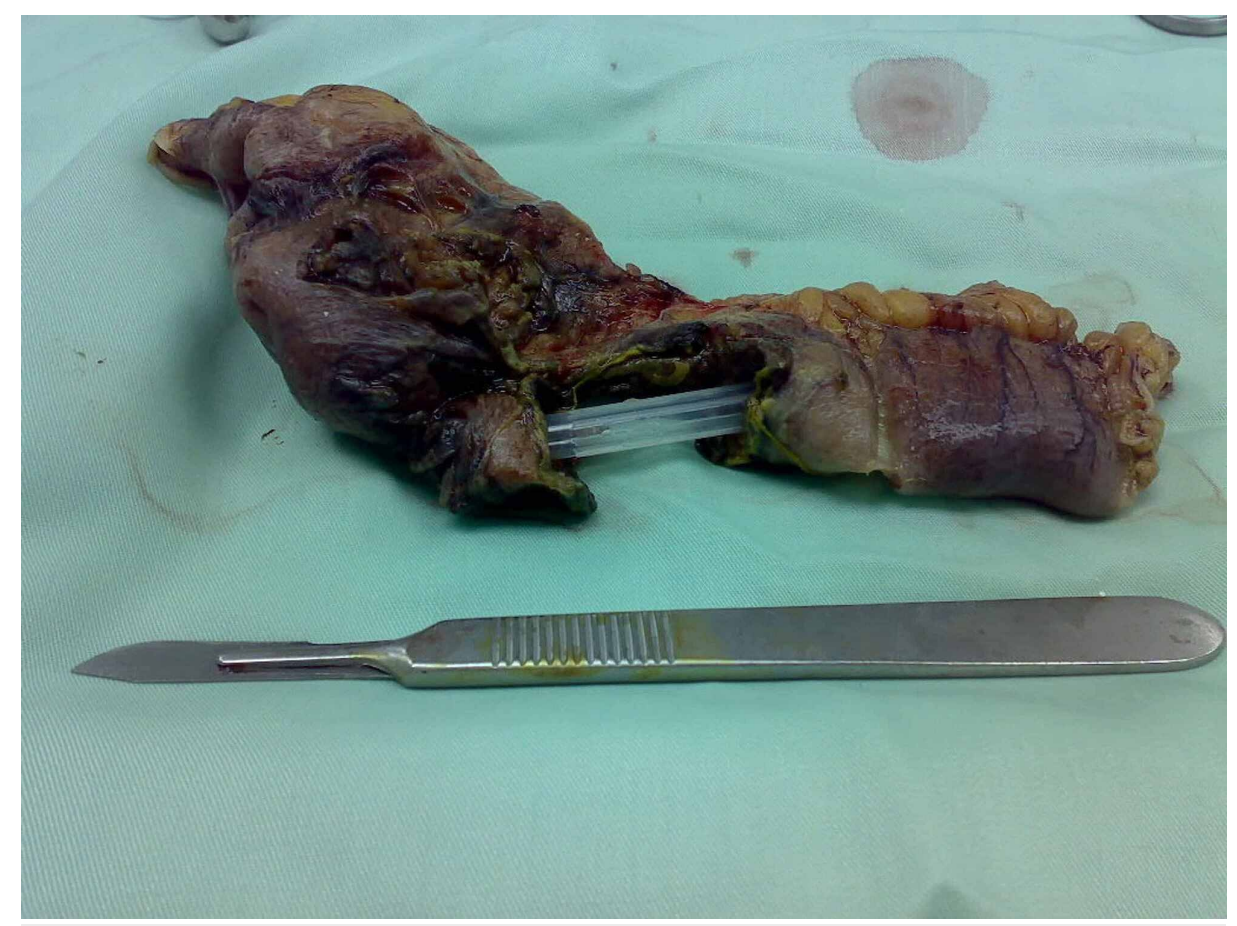

FIGURE 3: Surgical specimen showing the site of the perforated small bowel.

A laparotomy was carried out through an infra-umbilical midline incision, revealing perforated distal ileum, resection-anastomosis of the perforated segment of the bowel, peritoneal lavage was carried out, two Robinson drains were left in the peritoneal cavity, and the hernia was repaired by Lichtenstein technique (Figure 4). 


\section{Cureus}

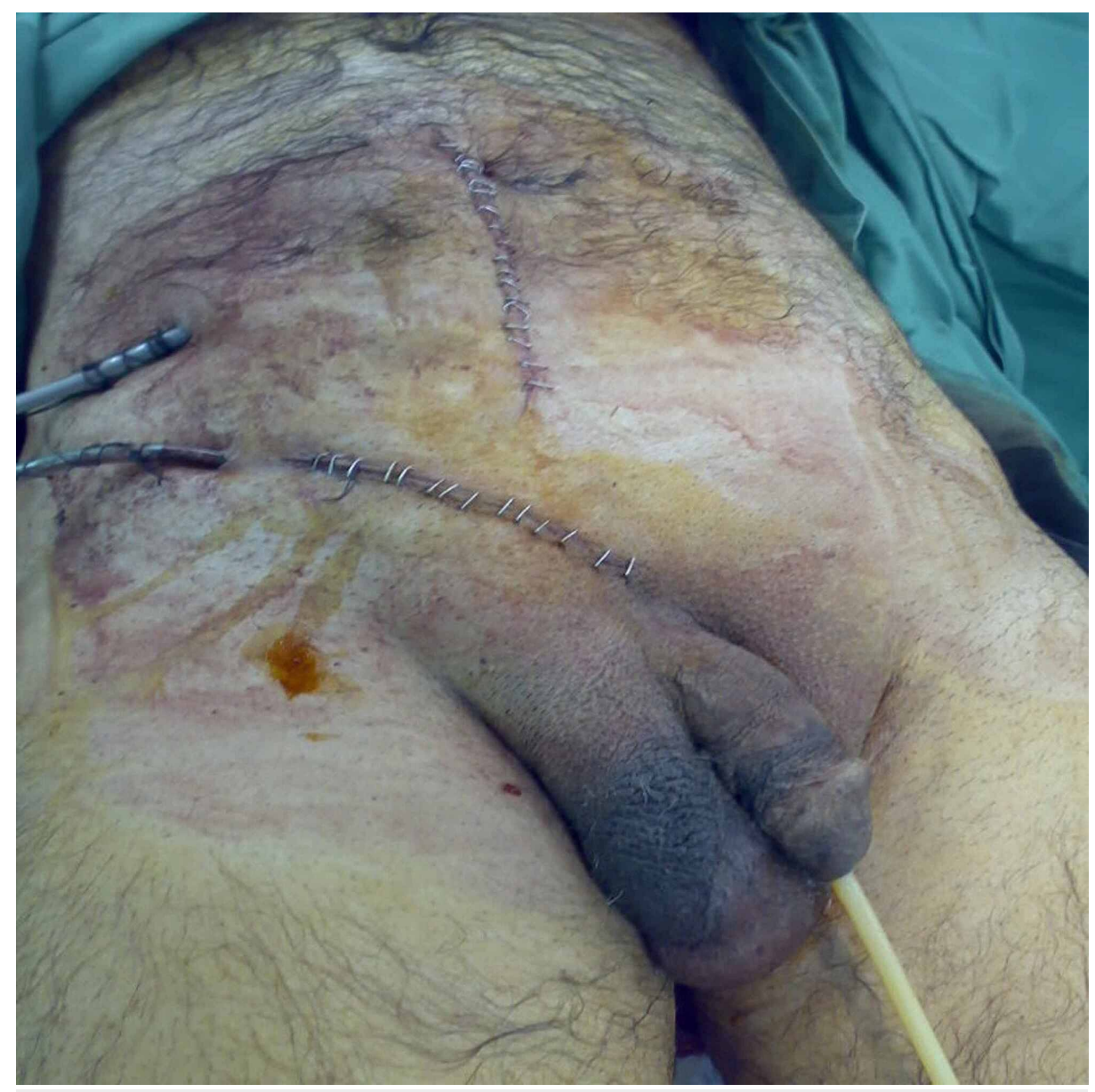

\section{FIGURE 4: Postoperative picture showing the right groin exploration incision as well as the laparotomy incision.}

The patient passed through a smooth postoperative period; he was discharged home on the fifth postoperative day and seen in the clinic after six weeks with no complications.

\section{Discussion}

While inguinal hernias are relatively common, with an estimated prevalence of $6 \%$ [2]; incarceration of the hernia only occurs in $10 \%$ of cases. Unfortunately, in some cases, incarceration can progress to intestinal obstruction, strangulation, infarction and subsequently perforation, which can lead to unfavourable outcome if not diagnosed and managed promptly $[3,4]$.

Incidence of strangulation varies from 3.25 to 7.16 per 100,000 population per annum [5]. When Gallegos et al. calculated strangulation incidence, based on lengths of medical history from onset of symptoms to diagnosis of strangulation they found that strangulation incidence raises with time from $2.8 \%$ at three months to $8.6 \%$ at five years [6]. On the contrary, Nyhus et al. noted that $10 \%$ to $20 \%$ of patients present with a strangulated inguinal hernia as the first presentation [7]. Also, McEntee et al. reported that one-third of patients usually present with manifestations of strangulation only a few days after discovering the presence of the hernia [8].

Watkin et al. reported that in their cohort the risk of strangulation was inversely related to the diameter of the hernia defect (the smaller the defect, the higher the risk of strangulation), they also reported that incidence of strangulation was only $3 \%$ in direct hernias [5]. On the contrary Kulacoglu et al. found that age is an important prognostic factor for strangulation, as they noted increased incidence of strangulation in patients older than 60 years, in comparison to those younger than 60 years. They also found that the average diameter of the transversalis fascia defect was $23.8 \mathrm{~mm}$, so the diameter of the fascial defect was found to have an impact on the incidence of strangulation. Still, they noted a significant difference in the incidence of strangulation between indirect hernia, which was $32.6 \%$ and direct inguinal hernias which was $10.3 \%$ [1].

When Hair et al. looked into intraoperative findings of patients presenting with strangulation they found that $50 \%$ of hernias emerged through an indirect defect, $30 \%$ were recurrent hernias, $10 \%$ emerged through a 
pantaloon hernia (having both direct and indirect components), and 10\% emerged through a direct hernia [9].

While it is well established that elective inguinal hernia mesh repair is associated with superior results when compared with Bassini repair; there has always been a debate regarding mesh repair in strangulated inguinal due to the fear of increased incidence of infection hernia. This debate was resolve following multiple studies confirming that even in cases with strangulated inguinal hernia, Lichtenstein "tension-free" mesh repair is safe and effective with low postoperative complications and recurrence rates [10,11].

In our case, the preoperative diagnosis was an incarcerated inguinal hernia; we initially thought that strangulation is unlikely due to the absence of systemic manifestations and signs of bowel obstruction and also the fact that strangulation is very rare with direct hernias. At operation, the hernia was found to be a direct one containing a strangulated perforated loop of the terminal ileum, a rather uncommon finding in a direct hernia. Resection anastomosis of the perforated segment of the bowel was carried out with uneventful intraoperative and postoperative courses.

\section{Conclusions}

Inguinal hernia is a common surgical condition accounting for a good number of elective as well as acute surgical admissions; for the experienced surgeon, diagnosis and repair should be straightforward; however, unexpected operative findings may be encountered requiring an expert approach. The urgent need to repair strangulated inguinal hernias should not have a negative impact on adequate preoperative imaging to ascertain an accurate diagnosis preoperatively and rule out concomitant intra-abdominal pathology. We recommend reporting direct inguinal hernia cases to have an extensive database which will allow us to come up with more informative recommendations.

\section{Additional Information \\ Disclosures}

Human subjects: Consent was obtained by all participants in this study. no ethical approval was required issued approval . Conflicts of interest: In compliance with the ICMJE uniform disclosure form, all authors declare the following: Payment/services info: All authors have declared that no financial support was received from any organization for the submitted work. Financial relationships: All authors have declared that they have no financial relationships at present or within the previous three years with any organizations that might have an interest in the submitted work. Other relationships: All authors have declared that there are no other relationships or activities that could appear to have influenced the submitted work.

\section{References}

1. Kulacoglu H, Kulah B, Hatipoglu S, Coskun F: Incarcerated direct inguinal hernias: a three-year series at a large volume teaching hospital. Hernia. 2000, 4:145-147. 10.1007/BF01207592

2. Slater R, Amatya U, Shorthouse AJ: Colonic carcinoma presenting as strangulated inguinal hernia: report of two cases and review of the literature. Tech Coloproctol. 2008, 12:255-258. 10.1007/s10151-008-0388-0

3. McFadyen BV, Mathis CR: Inguinal herniorraphy: complications and recurrences. Semin Laparosc Surg. 1994, 1:128-140. 10.1177/155335069400100208

4. Gallegos NC, Dawson J, Jarvis M, Hobsely M: Risk of strangulation in groin hernias . Br J Surg. 1991, 78:11711173. 10.1002/bjs.1800781007

5. Watkin D: Groin Hernias in the Adult Presenting as Emergencies . Bendavid R, Abrahamson J, Arregui ME, Flament JB, Phillips EH (ed): Abdominal Wall Hernias. Springer, New York, NY; 2001. 10.1007/978-1-44198574-3_84

6. Gallegos NC, Dawson J, Javis M, Hobsley M: Risk of strangulation in groin hernias . Br J Surg. 1991, 78:11711173. 10.1002/bjs.1800781007

7. Nyhus LM, Pollak R, Bombeck CT, Donahue PE: The preperitoneal approach and prosthetic buttress repair for recurrent hernia. The evolution of a technique. Ann Surg. 1988, 208:733-737. 10.1097/00000658198812000-00010

8. McEntree GP, O'Carroll A, Mooney B, Egan TJ, Delaney PV: Timing of strangulation in adult hernias. Br J Surg. 1989 Jul, 76:725-726. 10.1002/bjs.1800760724

9. Hair A, Paterson C, Wright D, Baxter JN, O’Dwyer PJ: What effect does the duration of an inguinal hernia have on patient symptoms?. J Am Coll Surg. 2001, 193:125-129. 10.1016/S1072-7515(01)00983-8.

10. Papaziogas B, Lazaridis C, Makris J, et al.: Tension-free repair versus modified Bassini technique (Andrews technique) for strangulated inguinal hernia: a comparative study. Hernia. 2005, 9:156-159. 10.1007/s10029004-0311-9

11. Elsebae MM, Nasr M, Said M: Tension-free repair versus Bassini technique for strangulated inguinal hernia: a controlled randomized study. Int J Surg. 2008, 6:302-305. 10.1016/j.ijsu.2008.04.006 